UNIVERSITYOF

PORTSMOUTH

Working Papers in Economics \& Finance 2021-03

\title{
Interest Rate Swaps and the Trans- mission Mechanism of Monetary Policy: A Quantile Connectedness Ap- proach
}

Ioannis Chatziantoniou, University of Portsmouth David Gabauer, Software Competence Center Hagenberg Alexis Stenfors, University of Portsmouth 


\title{
Interest Rate Swaps and the Transmission Mechanism of Monetary Policy: A Quantile Connectedness Approach
}

\author{
Ioannis Chatziantoniou ${ }^{\dagger}$, David Gabauer ${ }^{\ddagger}$, and Alexis Stenfors ${ }^{\dagger, *}$ \\ ${ }^{\dagger}$ Economics and Finance Subject Group, University of Portsmouth, Portsmouth Business School, Portland \\ Street, Portsmouth, PO1 3DE, United Kingdom. \\ ${ }^{\ddagger}$ Data Analysis Systems, Software Competence Center Hagenberg, Softwarepark 21, 4232 Hagenberg, Austria. \\ *Corresponding Author. E-mail: alexis.stenfors@port.ac.uk.
}

\begin{abstract}
We investigate 1-year interest rate swaps on USD, EUR, JPY and GBP between 2005 and 2020 utilising a quantile connectedness model. This approach allows for a nuanced investigation of connectedness and adds to understanding the monetary policy transmission mechanism within a highly integrated international financial system. Substantial interest rate changes (in either direction) matter for connectedness in financial markets. The results also indicate which currency drives developments depending on the direction of the change in interest rates.
\end{abstract}

Keywords: Interest Rate Swaps; Monetary Policy Transmission Mechanism; Quantile Vector Autorergression.

JEL codes: C51; E43; F65; G15. 


\section{Introduction}

International bond yield movements are highly correlated (Ilmanen, 1995; Sutton, 2000). However, the correlation between term premia of G7 government bonds is time-varying and seems to have increased over time in line with the integration of international financial markets since the 1980s (Dahlquist and Hasseltoft, 2013). In particular, co-movements in interest rates appear to increase during episodes of high volatility and stress in financial markets (Johansson, 2008; Chatziantoniou et al., 2020). Such periods are typically associated with substantial interest rate changes, prompted by surging risk premia and (expected) accommodative monetary policy decisions by central banks to alleviate frictions in the financial system. Given that major moves in financial markets tend to be driven by either very negative or very positive changes in fundamental variables such as interest rates, in this study, we utilise the recently developed quantile connectedness approach to capture both the direction and the magnitude of interest rate changes. In this respect, we investigate (i) the impact of the magnitude of interest rate changes in the extent of connectedness in global interest rate swap markets, (ii) whether the impact of either negative (expansionary episodes) or positive (contractionary episodes) changes, is symmetric or not and (iii) the role of each market as a net transmitter or net recipient of spillover shocks across the variables of this network. By introducing a magnitude-dimension, our paper adds to the literature on the international transmission mechanism of monetary policy and connectedness in fixed income markets. In particular, we further elucidate some of the challenges of independent monetary policy within a global and increasingly interlinked financial system.

\section{Data}

\subsection{Data description}

We use daily closing prices of 1-year interest rate swaps (IRSs) between 2005 and 2020 and study the four most actively traded currencies: USD, EUR, JPY and GBP (see Figure 1). In terms of notional amounts outstanding, these accounted for $76.0 \%$ of the global IRS market in 2020 (BIS, 2020). The data is obtained from Bloomberg. Utilising 1-year IRSs, rather than official central bank rates or bonds, has three main advantages. First, the term to maturity incorporates the level of the current policy rate (which tends to be sticky) and expected changes in the near future. Second, IRSs incorporate both credit and liquidity strains, as observed in the money markets. Third, in contrast with either T-bills or bonds, the IRS market is unaffected by safe-haven buying, squeezes and other securities-related phenomena.

[ADD FIGURE 1 AROUND HERE.] 


\section{Methods}

We employ the quantile connectedness approach proposed by Ando et al. (2018) to examine the quantile propagation mechanism of 1-year IRSs. To calculate all connectedness metrics, we first estimate a quantile vector autoregression, $\mathrm{QVAR}(\mathrm{p})$, which can be outlined as follows:

$$
\boldsymbol{y}_{t}=\boldsymbol{\mu}(\tau)+\sum_{j=1}^{p} \boldsymbol{\Phi}_{j}(\tau) \boldsymbol{y}_{t-j}+\boldsymbol{u}_{t}(\tau)
$$

$\boldsymbol{y}_{t}$ and $\boldsymbol{y}_{t-j}$ are $k \times 1$ dimensional endogenous variable vectors, $\tau$ is between $[0,1]$ and represents the quantile of interest, $p$ stands for the lag length of the QVAR model, $\boldsymbol{\mu}(\tau)$ is a $k \times 1$ dimensional conditional mean vector, $\boldsymbol{\Phi}_{j}(\tau)$ is a $k \times k$ dimensional QVAR coefficient matrix, and $\boldsymbol{u}_{t}(\tau)$ demonstrates the $k \times 1$ dimensional error vector which has a $k \times k$ dimensional variance-covariance matrix, $\boldsymbol{\Sigma}(\tau)$. To transform the $\operatorname{QVAR}(\mathrm{p})$ to its $\operatorname{QVMA}(\infty)$ representation, we use Wold's theorem: $\boldsymbol{y}_{t}=\boldsymbol{\mu}(\tau)+\sum_{j=1}^{p} \boldsymbol{\Phi}_{j}(\tau) \boldsymbol{y}_{t-j}+$ $\boldsymbol{u}_{t}(\tau)=\boldsymbol{\mu}(\tau)+\sum_{i=0}^{\infty} \mathbf{\Psi}_{i}(\tau) \boldsymbol{u}_{t-i}$.

Afterwards, the H-step ahead Generalised Forecast Error Variance Decomposition (GFEVD) of Koop et al. (1996) and Pesaran and Shin (1998) is calculated which illustrates the impact a shock in variable $j$ has on variable $i$ :

$$
\psi_{i j}^{g}(H)=\frac{\boldsymbol{\Sigma}(\tau)_{i i}^{-1} \sum_{h=0}^{H-1}\left(\boldsymbol{e}_{i}^{\prime} \boldsymbol{\Psi}_{h}(\tau) \boldsymbol{\Sigma}(\tau) \boldsymbol{e}_{j}\right)^{2}}{\sum_{h=0}^{H-1}\left(\boldsymbol{e}_{i}^{\prime} \boldsymbol{\Psi}_{h}(\tau) \boldsymbol{\Sigma}(\tau) \boldsymbol{\Psi}_{h}(\tau)^{\prime} \boldsymbol{e}_{i}\right)} \quad \tilde{\psi}_{i j}^{g}(H)=\frac{\psi_{i j}^{g}(H)}{\sum_{j=1}^{k} \phi_{i j}^{g}(H)}
$$

$\boldsymbol{e}_{i}$ represents a zero vector with unity on the $i$ th position. This normalisation leads to the following two equalities: $\sum_{j=1}^{k} \tilde{\psi}_{i j}^{g}(H)=1$ and $\sum_{i, j=1}^{k} \tilde{\psi}_{i j}^{g}(H)=k$.

To get the information of the overall impact variable $i$ has on all other variables $j$, the total directional connectedness TO others is computed:

$$
C_{i \rightarrow j}^{g}(H)=\sum_{j=1, i \neq j}^{k} \tilde{\psi}_{j i}^{g}(H)
$$

Subsequently, the impact of shocking all other variables $j$ on variable $i$ is evaluated by the total directional connectedness FROM others:

$$
C_{i \leftarrow j}^{g}(H)=\sum_{j=1, i \neq j}^{k} \tilde{\psi}_{i j}^{g}(H)
$$

The differences between the total directional connectedness TO others and the total directional connectedness FROM others results in the net total directional connectedness that can be regarded as the net influence variable $i$ has on the analyzed network.

$$
C_{i}^{g}(H)=C_{i \rightarrow j}^{g}(H)-C_{i \leftarrow j}^{g}(H)
$$


The last connectedness metric is the adjusted total connectedness index (TCI) of Chatziantoniou and Gabauer (2021) which ranges between $[0,1]$ :

$$
T C I(H)=\frac{\sum_{i, j=1, i \neq j}^{k} \tilde{\psi}_{i j}^{g}(H)}{k-1} .
$$

This measure is often used as a proxy for market risk as the higher the TCI is the higher is the degree of network interconnectedness.

\section{Findings and discussion}

Figure 2 illustrates the results for total dynamic connectedness. Warmer shades on the plot correspond to higher levels of connectedness. Connectedness is very strong both for very small (or negative) interest rate changes (below the $20 \%$ quantile) and for highly positive changes (above the $80 \%$ quantile). That is, the impact appears to be symmetric. Furthermore, the $50 \%$ quantile corresponds to the total average connectedness of the entire period. It assumes significant values at specific intervals (before 2009, around 2010 and towards the end of our sample). This indicates a somewhat cyclical pattern of connectedness across time, stemming from the fact that connectedness is highly event-dependent.

\section{[ADD FIGURE 2 AROUND HERE.]}

In turn, we focus on net directional results. These are presented in Figures 3-6. Warmer shades on these plots indicate a net-transmitting currency. In Figure 3, we note that USD has been steadily transmitting to all other currencies. Notable episodes include 2009 (following the GFC 2007-08) and 2012 (ending of resurging credit spreads in major economies). These results are in line with Rogers et al. (2018), who document that US unconventional monetary policy easing shocks in the post GFC-200708 period lowered not only domestic but also foreign (UK, German and Japanese) bond term premia. Finally, towards the end of our sample, the net transmitting role of USD is mainly driven by either very low or negative interest rate movements - which coincides with the 2019 reversal of the gradual monetary policy tightening in the US and the 2020 COVID-19 outbreak.

\section{[ADD FIGURE 3 AROUND HERE.]}

In Figure 4, we see that the EUR has assumed both roles over time. In general, negative interest rate changes can be associated with EUR assuming a net-receiving role. During the early part of the GFC 2007-08, EUR switched to a net transmitter of shocks, with transmission being traced mainly to the region of extreme quantiles. During the beginning of the European Debt Crisis (late 2009 - early 2010), it acts as a transmitter while, it assumes a net receiving role from late 2011 to 2013 , which is a period that coincides with a drop in IRS prices, a series of ECB rate cuts and a tightening of credit spreads. Since the COVID-19 outbreak, EUR retains a net transmitting role only for very positive (higher quantiles) interest rate changes. 


\section{[ADD FIGURE 4 AROUND HERE.]}

In Figure 5, we see that GBP has also shifted across time between a net transmitting and a net receiving role. In the aftermath of the 2016 Brexit referendum, GBP clearly assumes a net transmitting role. Since the COVID-19 outbreak, GBP has a net receiving role only for very low (or negative) interest rate change

\section{[ADD FIGURE 5 AROUND HERE.]}

Finally, in Figure 6, we note that JPY has been a persistent net recipient of shocks throughout the sample period. Japan has faced a low-interest-rate environment since the 1990s. Apparently, neither the launch of Abenomics in 2013 nor the adoption of yield curve control in 2016 appears to have had any significant impact on other major markets.

\section{[ADD FIGURE 6 AROUND HERE.]}

\section{Conclusion}

We investigate 1-year IRSs between 2005 and 2020 for USD, EUR, GBP, and JPY. We utilise the quantile connectedness approach, which allows for a considerably more nuanced investigation into how global interest rates and fixed income markets influence each other. In particular, we present results considering not only the role of each currency (net receiving/transmitting) across time but also whether this role is driven by highly positive or very low (or negative) interest rate changes. The latter sheds additional light on which currency drives developments in financial markets during periods of turbulence and stress in the international financial system.

\section{References}

Ando, T., Greenwood-Nimmo, M., and Shin, Y. (2018). Quantile connectedness: Modelling tail behaviour in the topology of financial networks. Available at SSRN 3164772.

BIS (2020). OTC derivatives outstanding, Table D7 (Interest rate derivatives). https://stats.bis.org/statx/srs/table/dr?f=pdf (March 3 2021).

Chatziantoniou, I. and Gabauer, D. (2021). EMU risk-synchronisation and financial fragility through the prism of dynamic connectedness. The Quarterly Review of Economics and Finance, 79:1-14.

Chatziantoniou, I., Gabauer, D., and Stenfors, A. (2020). From CIP-deviations to a market for risk premia: A dynamic investigation of cross-currency basis swaps. Journal of International Financial Markets, Institutions and Money, 69:101245.

Dahlquist, M. and Hasseltoft, H. (2013). International bond risk premia. Journal of International Economics, 90(1):17-32.

Ilmanen, A. (1995). Time-varying expected returns in international bond markets. The Journal of Finance, 50(2):481-506.

Johansson, A. C. (2008). Interdependencies among Asian bond markets. Journal of Asian Economics, $19(2): 101-116$. 
Koop, G., Pesaran, M. H., and Potter, S. M. (1996). Impulse response analysis in nonlinear multivariate models. Journal of Econometrics, 74(1):119-147.

Pesaran, H. H. and Shin, Y. (1998). Generalized impulse response analysis in linear multivariate models. Economics Letters, 58(1):17-29.

Rogers, J. H., Scotti, C., and Wright, J. H. (2018). Unconventional monetary policy and international risk premia. Journal of Money, Credit and Banking, 50(8):1827-1850.

Sutton, G. D. (2000). Is there excess comovement of bond yields between countries? Journal of International Money and Finance, 19(3):363-376.

Figure 1: 1-Year Interest Rate Swaps

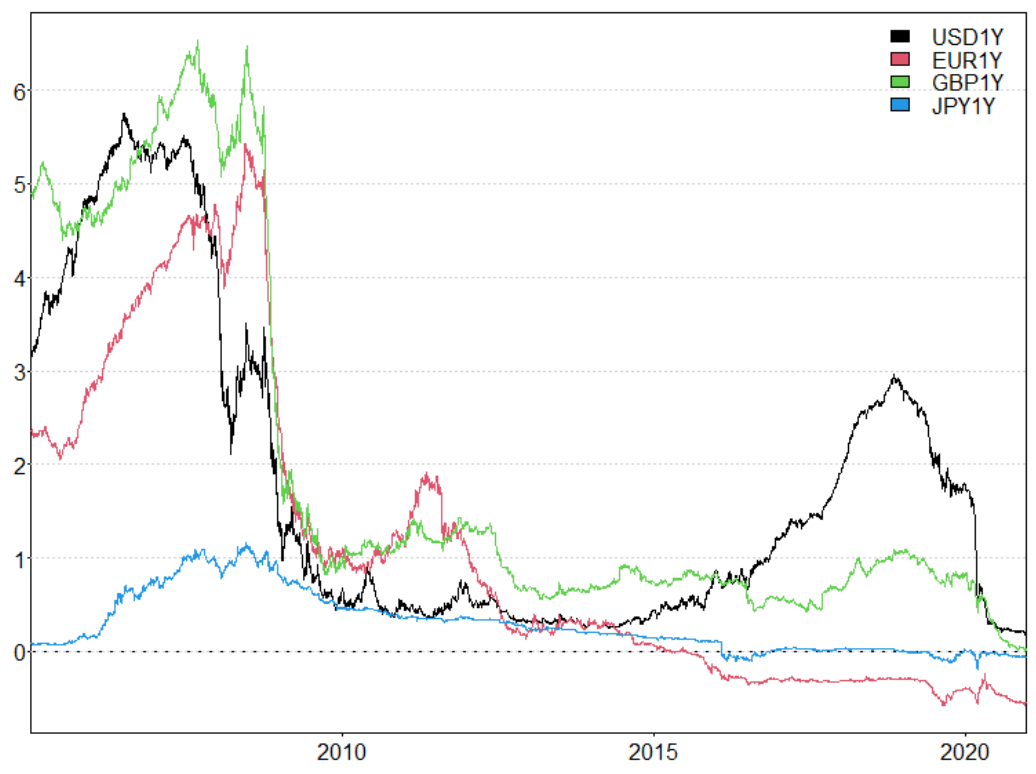

Figure 2: 1-Year Dynamic Total Connectedness

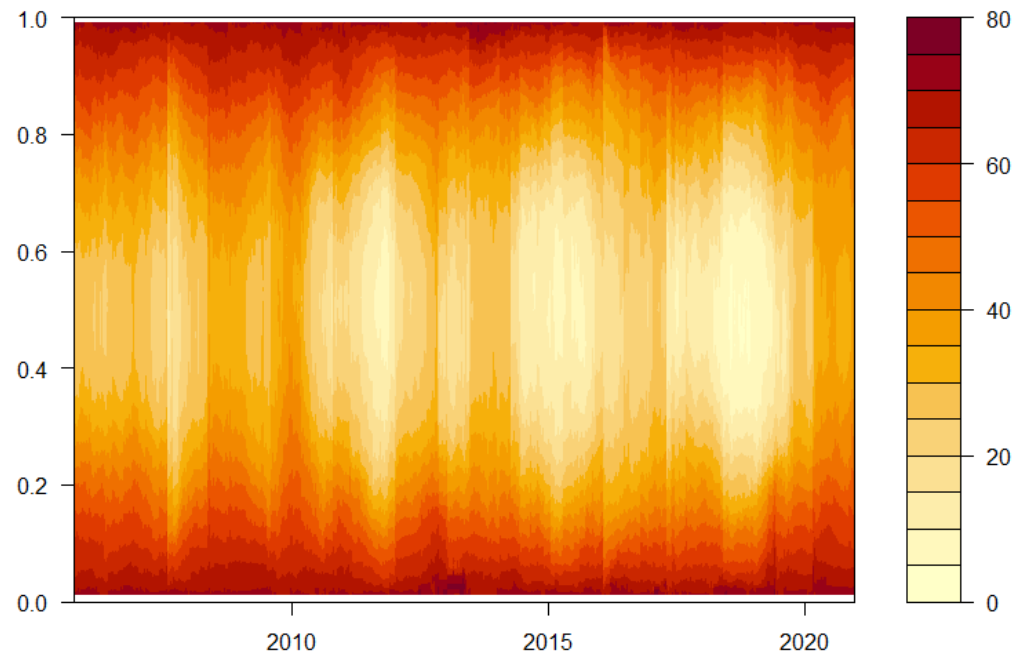

Notes: Results are based on a 200-days rolling-window QVAR model with lag length of order 1 (BIC) and a 20-step-ahead forecast. 
Figure 3: 1-Year Net Total Directional Connectedness (USD)

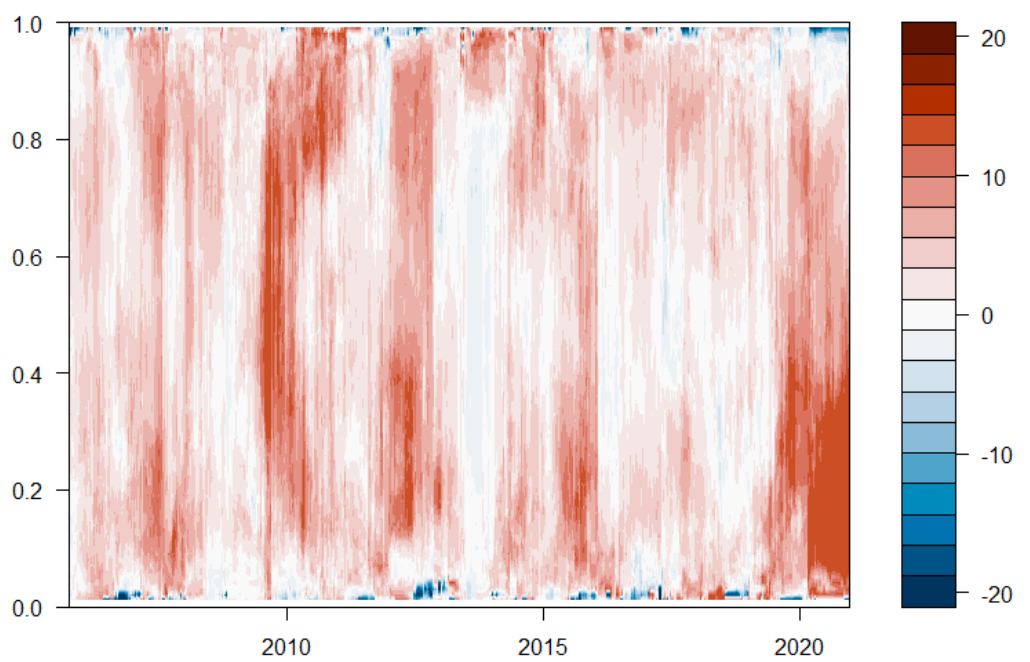

Notes: Results are based on a 200-days rolling-window QVAR model with lag length of order 1 (BIC) and a 20-step-ahead forecast.

Figure 4: 1-Year Net Total Directional Connectedness (EUR)

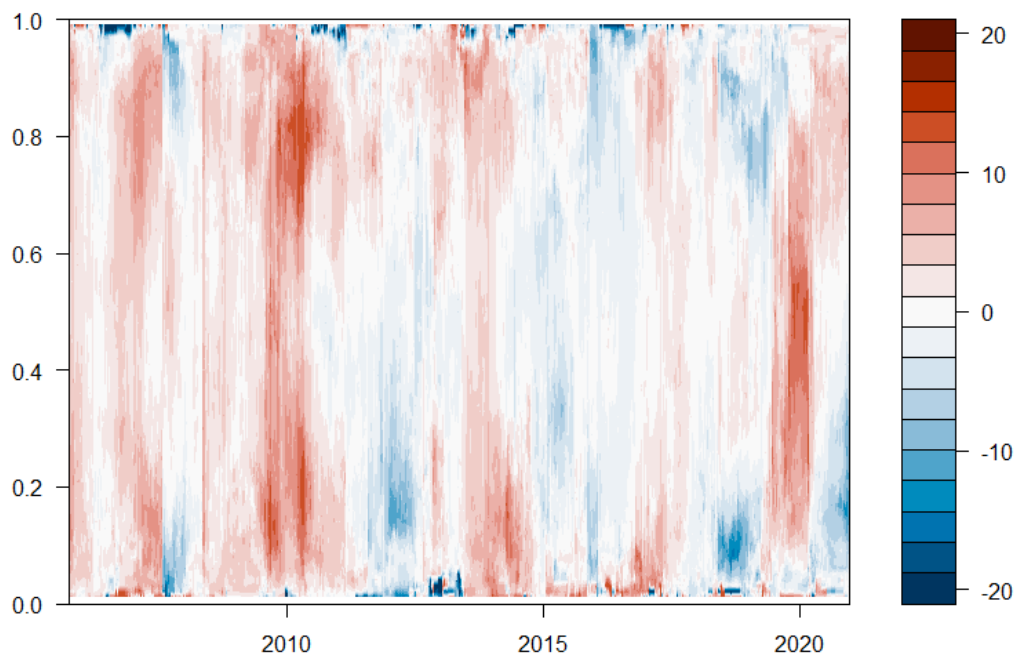

Notes: Results are based on a 200-days rolling-window QVAR model with lag length of order 1 (BIC) and a 20-step-ahead forecast. 
Figure 5: 1-Year Net Total Directional Connectedness (GBP)

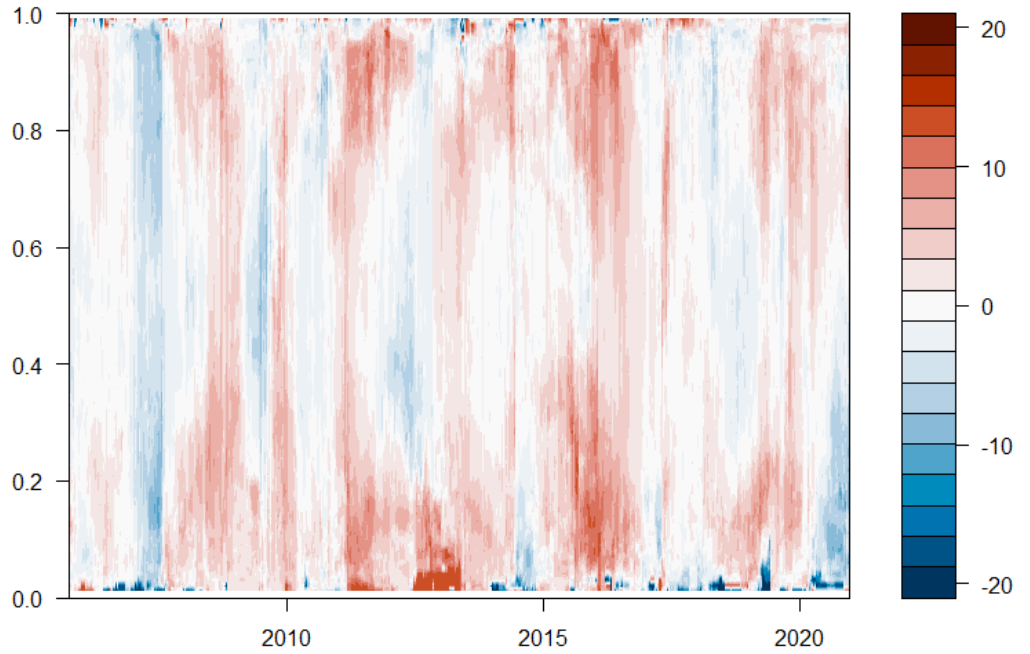

Notes: Results are based on a 200-days rolling-window QVAR model with lag length of order 1 (BIC) and a 20-step-ahead forecast.

Figure 6: 1-Year Net Total Directional Connectedness (JPY)

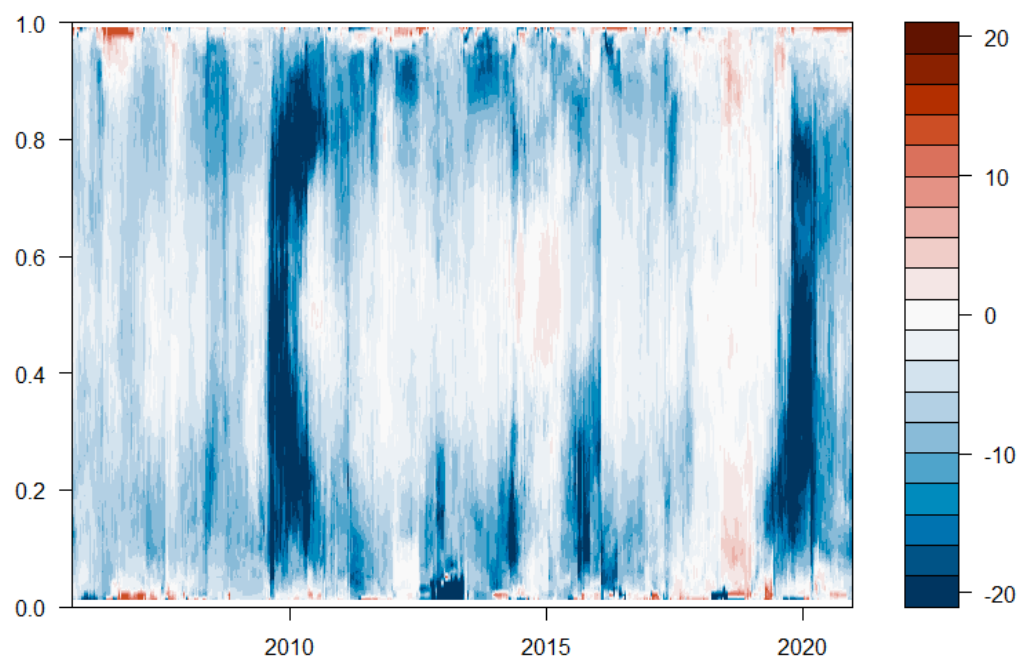

Notes: Results are based on a 200-days rolling-window QVAR model with lag length of order 1 (BIC) and a 20-step-ahead forecast. 